\title{
Guar gum and reduction of post-prandial glycaemia : effect of incorporation into solid food, liquid food, and both
}

\author{
By T. M. S. WOLEVER, D. J. A. JENKINS, R. NINEHAM AND \\ K. G. M. M. ALBERTI \\ University Laboratory of Physiology, Oxford and Department of the Regius Professor \\ of Medicine, Radcliffe Infirmary, Oxford, MRC Unit and Department of Gastroenterology, \\ Central Middlesex Hospital, London, Human Metabolism and Chemical Pathology Unit, \\ General Hospital, Southampton $\mathrm{SO}_{9}{ }_{4} \mathrm{XY}$
}

(Received 3I May 1978 - Accepted 13 December 1978)

\begin{abstract}
I. The influence of the dose and the form in which guar gum was given on the degree of 'flattening' of blood glucose curves was studied in five subjects using meals of bread and soup containing 5 or 10 g guar gum.

2. When $5 \mathrm{~g}$ guar gum was added to bread the peak increase of blood glucose was reduced by $4 \mathrm{I} \%$ $(P<0.002)$, with $5 \mathrm{~g}$ guar in soup, the reduction was $54 \%(P<0.001)$ while a reduction of $68 \%(P<0.00 \mathrm{I})$ was seen with $10 \mathrm{~g}$ guar gum ( $5 \mathrm{~g}$ in bread and $5 \mathrm{~g}$ in soup). The corresponding reduction in insulin peak increases were $37 \%(P<0.002), 50 \%(P<0.001)$ and $65 \%(P<0.00 \mathrm{I})$ respectively.

3. The difference between the two $5 \mathrm{~g}$ doses was not significant with respect to the reduction of the peak increases in blood glucose and serum insulin; however the difference between the $5 \mathrm{~g}$ dose in bread and the $10 \mathrm{~g}$ dose was significantly different $(P<0.02$ for glucose, $P<0.01$ for insulin).

4. The results indicate that as little as $5 \mathrm{~g}$ guar gum may reduce the glycaemia following a $45 \mathrm{~g}$ carbohydrate meal, but perhaps due to earlier and more complete mixing, guar gum is most effective when added to the liquid phase of the meal.
\end{abstract}

Guar gum, one of the gel-forming plant polysaccharides, has been shown to lower the postprandial glucose and insulin responses in both normal (Jenkins, Leeds et al. 1977) and diabetic (Jenkins et al. 1976) subjects and to reduce the $24 \mathrm{~h}$ urinary glucose output in diabetics (Jenkins, Wolever et al. 1977). Comparison of guar gum with other unabsorbable polysaccharides has also shown it to be the most effective in 'flattening' the blood glucose increase which follows $50 \mathrm{~g}$ oral glucose loads (Wolever et al. 1978). This action was demonstrated to be related to the ability of guar gum to increase the viscosity of aqueous solutions (Jenkins et al. 1978).

In view of the potential therapeutic use of this and other such agents in the treatment of diabetes, an attempt was made to define both the dose and the form in which guar gum might be given to be most effective in lowering the blood glucose level or at least preventing an excessive increase after a meal. We have therefore given meals containing guar gum in a solid food, bread, or a liquid food, soup, with total doses of guar gum of either 5 or ro $\mathrm{g}$.

\section{EXPERIMENTAL METHODS}

The approval of the hospital ethical committee was obtained for this study in which five normal volunteers (one female, four male; 20-34 years; $103 \pm 2 \%$ desirable weight, Diem \& Lentner, I972) took four different meals in random order on separate days after an overnight fast. Although there was significant heterogeneity between the subjects with respect to fasting blood glucose concentrations $(P<0 \cdot 0 \mathrm{I})$ this was not seen with respect to fasting insulin levels (Table I). After accounting for the variation between subjects there were no differences in the mean fasting blood glucose or serum insulin levels on the $4 \mathrm{~d}$ (Table $\mathrm{r}$ ). Each meal, taken over Io min, consisted of white bread and tomato soup. The test experiments contained $5 \mathrm{~g}$ guar gum added to bread (Apling et al. 1977), or $5 \mathrm{~g}$ guar gum added 
Table I. Mean fasting blood glucose ( $\mathrm{mmol} / \mathrm{l}$ ) and serum insulin ( $\mathrm{pmol} / \mathrm{l}$ )

(Values for each subject and each day with their standard errors and significances of heterogeneity)

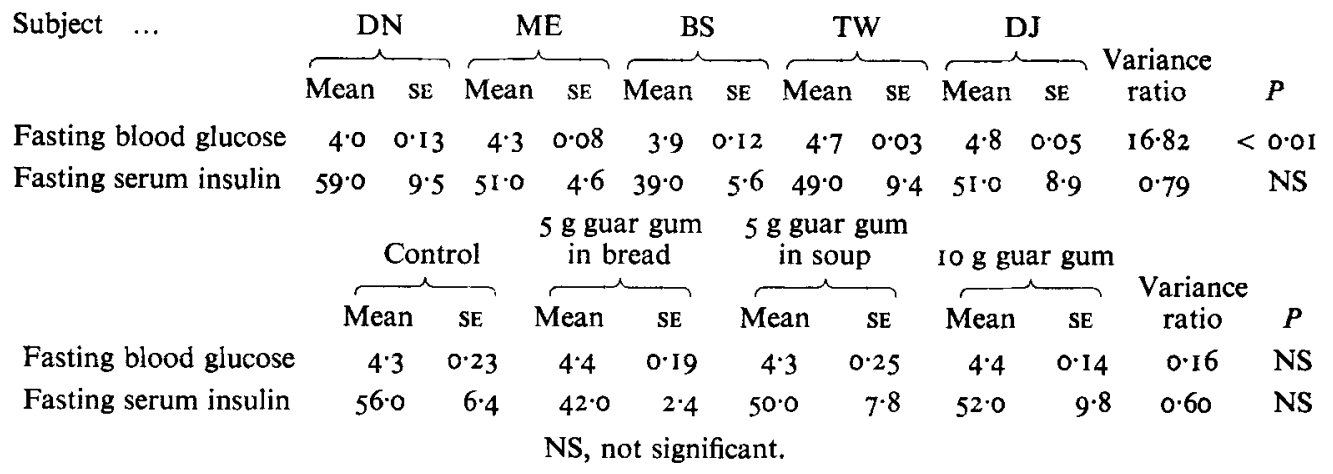

Table 2. Composition ( $\mathrm{g} /$ meal) of test and control meals

$\begin{array}{lccccc} & \text { Total } & \text { Fat } & \text { Protein } & \begin{array}{l}\text { Carbo- } \\ \text { hydrate }\end{array} & \text { Guar gum } \\ \begin{array}{l}\text { Tomato soup: } \\ \quad \text { Control }\end{array} & 300 \cdot 0 & 11 \cdot 4 & 2 \cdot 1 & 28 \cdot 8 & 0 \cdot 0 \\ \begin{array}{l}\text { Test } \\ \text { White bread: }\end{array} & 280 \cdot 0 & 11 \cdot 5 & 3 \cdot 4 & 24 \cdot 9 & 5 \cdot 1 \\ \quad \text { Control } & 41 \cdot 3 & 0 \cdot 5 & 3 \cdot 2 & 20 \cdot 6 & 0 \cdot 0 \\ \quad \begin{array}{l}\text { Test } \\ \text { Total for meals: }\end{array} & 62 \cdot 5 & 0 \cdot 5 & 4 \cdot 9 & 20 \cdot 6 & 5 \cdot 0 \\ \quad \text { Control soup, bread } & - & 11 \cdot 9 & 5 \cdot 3 & 49 \cdot 4 & 0 \cdot 0 \\ \quad \text { Test soup, control bread } & - & 12 \cdot 0 & 6 \cdot 6 & 45 \cdot 5 & 5 \cdot 1 \\ \quad \text { Control soup, test bread } & - & 11 \cdot 9 & 7 \cdot 0 & 49 \cdot 4 & 5 \cdot 0 \\ \text { Test soup, test bread } & - & 12 \cdot 0 & 7 \cdot 3 & 45 \cdot 5 & 10 \cdot 1\end{array}$

to soup, or Io g guar gum, added as $5 \mathrm{~g}$ to both the bread and the soup. The compositions of the four meals are shown in Table 2.

Blood samples were taken in the fasting state and at $15,30,45,60,90,120$ and $180 \mathrm{~min}$ after the start of each meal for the analysis of glucose (Werner et al. 1970) and insulin (Soeldner \& Slone, 1965).

The results are expressed as mean values with their standard errors, and the significance tests performed utilizing an estimated true standard error calculated by analysis of variance for a randomized block design (Bailey, 1964) by reference to Student's $t$ distribution .

Areas under the curve for glucose and insulin were derived from the 0-1 20 min values.

\section{RESULTS}

Allowing for the variability between subjects, there was significant heterogeneity between the mean blood glucose values at $30 \mathrm{~min}(P<0.0 \mathrm{r})$ and $45 \mathrm{~min}(P<0.05)$, between the mean serum insulin values at $30 \mathrm{~min}(P<0.01), 45 \mathrm{~min}(P<0.05)$ and $60 \mathrm{~min}(P<0.05)$ (Fig. I), between the mean areas under the glucose $(P<0.05)$ and insulin $(P<0.05)$ curves from $0-120 \mathrm{~min}$, and between the mean peak increases of glucose $(P<0.0 \mathrm{I})$ and insulin $(P<0.01)$ (Table 3$)$.

Guar gum in bread $(5 g)$. Allowing for the variability between subjects, after the meal containing $5 \mathrm{~g}$ guar gum in bread, with respect to the control meal, the mean blood glucose levels were significantly reduced at $30 \mathrm{~min}$ by $10 \%(P<0.0 \mathrm{I})$ and at $45 \mathrm{~min}$ by $15 \%$ $(P<0.0 I)$ (Fig. I); the mean area under the curve and peak increase of blood glucose were 
Table 3. Areas under the curve from 0-120 min and mean peak increases of blood glucose and serum insulin

(Mean values with their standard errors, variance ratios and significance of heterogeneity)

\begin{tabular}{|c|c|c|c|c|c|c|c|c|c|c|}
\hline \multirow[b]{3}{*}{ Blood glucose } & \multicolumn{2}{|c|}{ Control } & \multicolumn{2}{|c|}{$\begin{array}{l}5 \mathrm{~g} \text { guar gum } \\
\text { in bread }\end{array}$} & \multicolumn{2}{|c|}{$\begin{array}{l}5 \text { g guar gum } \\
\text { in soup }\end{array}$} & \multicolumn{2}{|c|}{ Io g guar gum } & \multirow{3}{*}{$\begin{array}{l}\text { Variance } \\
\text { ratio }\end{array}$} & \multirow[b]{2}{*}{$P$} \\
\hline & Mean & SE & Mean & SE & Mean & $\mathrm{SE}$ & Mean & SE & & \\
\hline & & & & & & & & & & \\
\hline $\begin{array}{l}\text { Areas under curve } \\
(\mathrm{mmol} \mathrm{h} / \mathrm{l})\end{array}$ & $1 \cdot 58$ & 0.34 & 0.91 & 0.10 & 0.73 & 0.17 & 0.75 & 0.33 & 3.77 & $<0.05$ \\
\hline $\begin{array}{r}\text { Peak rises } \\
(\mathrm{mmol} / \mathrm{l})\end{array}$ & $2 \cdot 17$ & 0.38 & $I \cdot 29$ & 0.23 & $1 \cdot 00$ & 0.25 & 0.70 & 0.21 & $9 \cdot 19$ & $<0.01$ \\
\hline Serum insulin & & & & & & & & & & \\
\hline $\begin{array}{l}\text { Areas under curve } \\
(\mathrm{pmol} / \mathrm{l})\end{array}$ & 289 & 55 & 228 & 39 & 147 & 44 & 118 & 23 & $5 \cdot 69$ & $<0.05$ \\
\hline $\begin{array}{l}\text { Peak rises } \\
(\mathrm{pmol} / \mathrm{l})\end{array}$ & 379 & 50 & 240 & 20 & 190 & 74 & I3I & 24 & 10.01 & $<0.01$ \\
\hline
\end{tabular}

significantly reduced by $44 \%(P<0.01)$ and $41 \%(P<0.002)$ respectively (Table 3$)$; the mean serum insulin levels were significantly reduced at $30 \mathrm{~min}$ by $30 \%(P<0.00 \mathrm{I})$, at $45 \mathrm{~min}$ by $34 \%(P<0.00 \mathrm{I})$ and at $60 \mathrm{~min}$ by $40 \%(P<0.00 \mathrm{I})$ (Fig. I); and the mean peak increase in serum insulin was significantly reduced by $37 \%(P<0.002)$ (Table 3 ).

Guar gum in soup $(5 \mathrm{~g})$. Allowing for the variability between subjects, after the meal containing $5 \mathrm{~g}$ guar gum in soup, with respect to the control meal, the mean blood glucose levels were significantly reduced at $30 \mathrm{~min}$ by $23 \%(P<0.00 \mathrm{I})$ and $45 \mathrm{~min}$ by $15 \%$ $(P<0.0 \mathrm{I})$ (Fig. I); the mean area under the curve and peak increase of blood glucose were both significantly reduced by $54 \%(P<0.002$, and $P<0.00$ I respectively) (Table 3$)$; the mean serum insulin levels were significantly reduced at $30 \mathrm{~min}$ by $62 \%(P<0.001)$, at $45 \mathrm{~min}$ by $36 \%(P<0.0 \mathrm{I})$ and at $60 \mathrm{~min}$ by $35 \%(P<0.0 \mathrm{I})$ (Fig. I); and the mean area under the curve and peak increase of serum insulin were significantly reduced by $49 \%$ $(P<0.00 \mathrm{I})$ and $50 \%(P<0.00 \mathrm{r})$ respectively (Table 3$)$.

Guar gum in both bread and soup (total $\mathrm{IO} g$ ). Allowing for the variability between subjects, after the meal containing $10 \mathrm{~g}$ guar, with respect to the control meal, the mean blood glucose levels were significantly reduced at $30 \mathrm{~min}$ by $2 \mathrm{I} \%(P<0.00 \mathrm{I})$ and $45 \mathrm{~min}$ by $19 \%$ $(P<0.002)$ (Fig. I); the mean area under the curve and peak increase of blood glucose were significantly reduced by $52 \%(P<0.002)$ and $68 \%(P<0.00 \mathrm{I})$ respectively (Table 3$)$; the mean serum insulin levels were significantly reduced at $30 \mathrm{~min}$ by $59 \%(P<0.00 \mathrm{I})$, at $45 \mathrm{~min}$ by $61 \%(P<0.00 \mathrm{I})$ and at $60 \mathrm{~min}$ by $49 \%(P<0.00 \mathrm{I})$ (Fig. I) and the mean area under the curve and peak increase of serum insulin were significantly reduced by $59 \%$ $(P<0.00 \mathrm{I})$ and $65 \%(P<0.00 \mathrm{r})$ respectively (Table 3$)$.

Differences between meals containing guar gum. After accounting for the variability between subjects, following the meals containing $5 \mathrm{~g}$ guar gum in soup only and that containing a total of $10 \mathrm{~g}$ guar gum, when compared with the meal containing $5 \mathrm{~g}$ guar gum in bread only, respectively, the mean blood glucose levels were reduced at $30 \mathrm{~min}$ by $\mathrm{I} 5 \%$ $(P<0.002)$ and I $2 \%(P<0.01)$ (Fig. 1$)$; the mean peak increases of blood glucose were reduced by $22 \%$ (not significant) and $46 \%(P<0.02)$ (Table 3$)$; the mean serum insulin levels were reduced at $30 \mathrm{~min}$ by $46 \%(P<0.00 \mathrm{I})$ and $42 \%(P<0.00 \mathrm{r})$, and at $45 \mathrm{~min}$ by $3 \%$ (not significant) and $41 \%(P<0.05)$ (Fig. I); and the mean areas under the curve and peak increases of serum insulin were reduced by $35 \%(P<0.05)$ and $48 \%(P<0.01)$, and $21 \%$ (not significant) and $45 \%(P<0.01)$ (Table 3$)$ respectively.

The only significant difference between the meal containing $5 \mathrm{~g}$ guar gum in soup only 


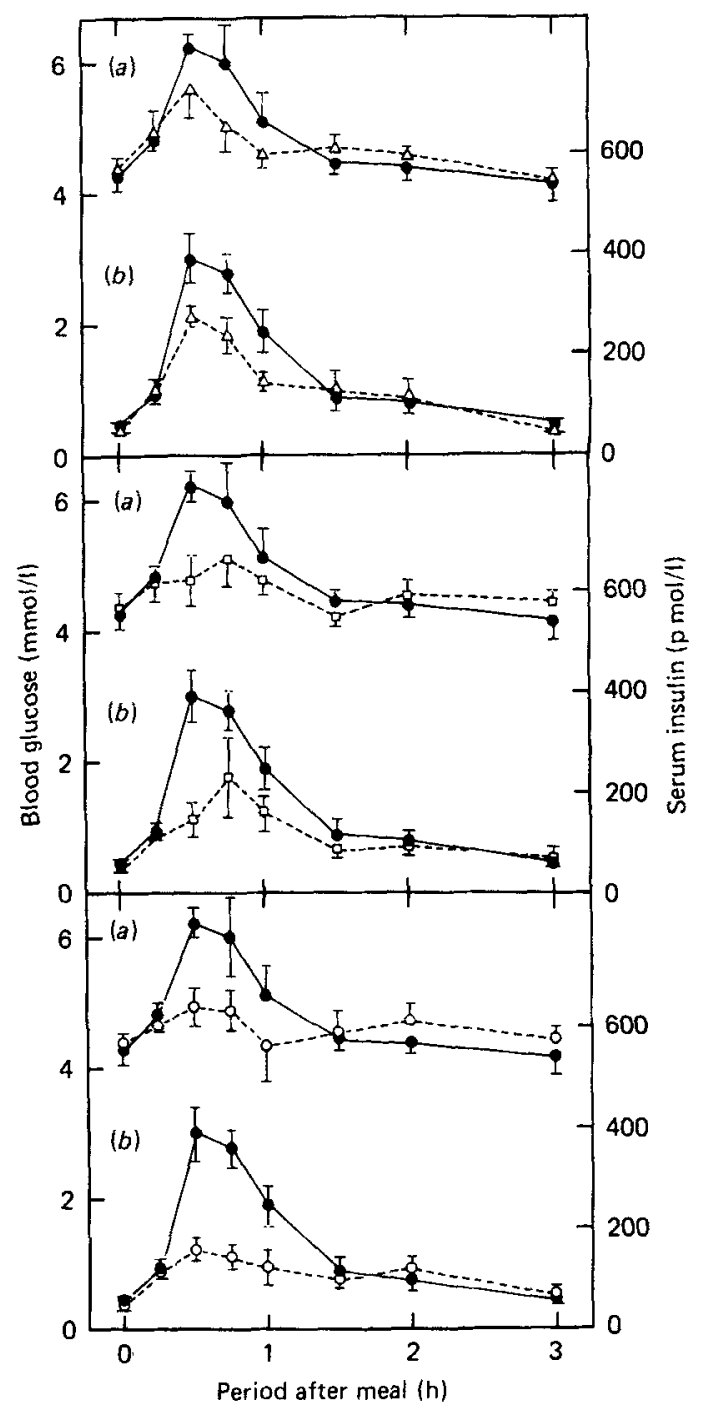

Fig. I. Mean (a) blood glucose ( $\mathrm{mmol} / \mathrm{l})$ and $(b)$ serum insulin (pmol/l; five subjects) after taking a control meal (-) or test meals of bread and soup containing either $5 \mathrm{~g}$ guar gum in the bread $(\triangle--\triangle), 5 \mathrm{~g}$ guar gum in the soup $(\square-\cdots-\square)$ or $10 \mathrm{~g}$ guar $(5 \mathrm{~g}$ in both the bread and the soup) $(\mathrm{O}-\mathrm{O})$. For details of meals, see Table $\mathrm{I}$ and p. 505. The points represent mean values, with their standard errors represented by vertical bars.

and that containing $10 \mathrm{~g}$ guar gum in total was, after accounting for the variability between subjects, a significantly reduced insulin level at $45 \mathrm{~min}$ after $10 \mathrm{~g}$ guar gum when compared with the $5 \mathrm{~g}$ dose $(39 \%, P<0.05)$ (Fig. I).

\section{DISCUSSION}

This study showed that as little as $5 \mathrm{~g}$ guar gum in bread significantly reduced the postprandial glycaemia and insulinaemia which followed a $45 \mathrm{~g}$ carbohydrate meal. When $5 \mathrm{~g}$ 
guar gum was taken in the form of soup, however, the effects on blood glucose and serum insulin were substantially improved. The differences between the two meals containing $5 \mathrm{~g}$ guar gum reached significance with respect to the mean blood glucose and serum insulin levels at $30 \mathrm{~min}$ and the mean area under the insulin curve.

Guar gum is not fully hydrated in bread or other semi-dry foods, but due to the convenience of such foods, it was potentially important to see whether they were therapeutically effective 'vehicles' for guar gum. Partly-hydrated guar gum forms lumps when added to other liquids and needs much mixing to form a homogeneous gel. If viscosity was of importance in the action of guar gum (Jenkins et al. 1978), then soup or foods which were already hydrated would be expected to be most effective in 'flattening' the post-meal blood glucose increase. The latter was indeed found to be the situation in this study.

Although the meal containing $10 \mathrm{~g}$ guar gum reduced both the peak increases in glucose and insulin and the area under the curve for insulin to a significantly greater extent than did $5 \mathrm{~g}$ guar in bread, the improvement over the meal containing $5 \mathrm{~g}$ guar in soup was smaller and not significant. However, when comparing the meals containing either $5 \mathrm{~g}$ guar gum in soup or Io g guar gum with that containing $5 \mathrm{~g}$ guar gum in bread, the differences were more significant after the $10 \mathrm{~g}$ dose, suggesting that it may have had a more consistent effect.

It is of interest in the comparison of results with guar-gum-containing bread and soup that when guar gum was added to the soup there was an alteration in the pattern of the glucose and insulin responses with a delay in the peak increases. This might well have been due to more complete gastric mixing of the guar gum when given in the soup, resulting in guar gum entering the duodenum with the first part of the meal and so being present to delay the early absorption of carbohydrate. Another marker of slower absorption may well be the increase and its correlation with viscosity in the blood glucose concentration $2 \mathrm{~h}$ after glucose tolerance tests containing gel-forming dietary fibre (Jenkins et al. 1978). Progressive improvement in the ability to delay absorption after the meals containing $5 \mathrm{~g}$ guar gum in bread, soup, and both might therefore be reflected in the progressive increases in blood glucose levels which occurred 2 and $3 \mathrm{~h}$ after the respective meals, and may explain the apparent secondary peaks of blood glucose which are seen in Fig. I.

Guar gum, although it is a gel-forming polysaccharide, is included under the broad heading of dietary fibre, being of plant origin and not digested in the human small intestine (Trowell et al. 1976). Other forms of dietary fibre have recently been used in the treatment of diabetes. High-carbohydrate, high-fibre diets consisting largely of unrefined cereals, legumes, and vegetables have been shown to allow withdrawal of insulin therapy in patients who previously had been maintained on low doses (Kiehm et al. 1976; Douglass \& Rasgon, 1976). Addition of a fibre-enriched bread (largely as cellulose) resulted in a reduction in mean post-prandial blood sugar levels during the day (Miranda \& Horwitz, 1977). Bread has, in both these instances, been the major 'vehicle' for addition of fibre to the diet and there is no doubt that if fibre is effective in this form, then bread provides a very versatile food in terms of transportation and meal formulation. The present results suggest that higher levels of fibre addition may be necessary for the gel-forming types of dietary fibre to be effective in bread than if given in a more hydrated form.

We conclude that addition of as little as $5 \mathrm{~g}$ guar gum may reduce the insulin and glucose response to a $45 \mathrm{~g}$ carbohydrate meal and that this effect is most marked when guar gum is given in hydrated form.

The authors wish to thank Mr Paddy Apling for supplying the bread, and Miss L. J. Hinks for performing the insulin assays. Soup was provided by H. J. Heinz \& Co. Ltd, Hayes Park, Middlesex. K.G.M.M.A. and T.M.S.W. were in receipt of grants from the British Diabetic Association. 


\section{REFERENCES}

Apling, E. C., Leeds, A. R., Wolever, T. M. S. \& Jenkins, D. J. A. (1977). Lancet ii, 975.

Bailey, N. T. J. (1964). Statistical Methods in Biology. London: English Universities Press Ltd.

Diem, K. \& Lentner, C. (1972). Documenta Geigy; Scientific Tables. Basle, Switzerland: Documenta Geigy. Douglass, J. \& Ragson, I. (1976). Lancet ii, 1306.

Jenkins, D. J. A., Leeds, A. R., Gassull, M. A., Cochet, B. \& Alberti, K. G. M. M. (1977). Ann. int. Med. 86, 20.

Jenkins, D. J. A., Leeds, A. R., Gassull, M. A., Wolever, T. M. S., Goff, D. V., Alberti, K. G. M. M. \& Hockaday, T. D. R. (1976). Lancet ii, I72.

Jenkins, D. J. A., Wolever, T. M. S., Hockaday, T. D. R., Leeds, A. R., Howarth, R., Bacon, S., Apling, E. C. \& Dilawari, J. (I977). Lancet ii, 779.

Jenkins, D. J. A., Wolever, T. M. S., Leeds, A. R., Gassull, M. A., Haisman, P., Dilawari, J. B., Goff, D. V., Metz, G. L. \& Alberti, K. G. M. M. (1978). Br. med. J. i, I 392.

Kiehm, M. D., Anderson, J. W. \& Ward, K. (1976). Am. J. clin. Nutr. 29, 895.

Miranda, P. M. \& Horwitz, D. J. (1977). Diabetes, 26, Suppl. I, 356.

Soeldner, J. S. \& Slone, D. (1965). Diabetes 14, 77 I.

Trowell, H. C., Southgate, D. A. T., Wolever, T. M. S., Leeds, A. R., Gassull, M. A. \& Jenkins, D. J. A. (1976). Lancet i, 967.

Werner, W., Rey, H. G. \& Wielenger, H. Z. (1970). Z. Analyt. Chem. 252, 224.

Wolever, T. M. S., Jenkins, D. J. A., Leeds, A. R., Gassull, M. A., Dilawari, J. B., Goff, D. V., Mety, G. L. \& Alberti, K. G. M. M. (1978). Proc. Nutr. Soc. 37, 28 A. 